\title{
Pharmacological and therapeutic directions in ADHD: Specificity in the PFC Florence Levy
}

Address: School of Psychiatry, University of New South Wales, Prince of Wales Hospital, Sydney, NSW 2031, Australia

Email: Florence Levy - f.levy@unsw.edu.au

Published: 28 February 2008

Behavioral and Brain Functions 2008, 4:12 doi:I0.1 186/1744-908I-4-12
Received: 21 October 2007

Accepted: 28 February 2008

This article is available from: http://www.behavioralandbrainfunctions.com/content/4/I/I2

(c) 2008 Levy; licensee BioMed Central Ltd.

This is an Open Access article distributed under the terms of the Creative Commons Attribution License (http://creativecommons.org/licenses/by/2.0), which permits unrestricted use, distribution, and reproduction in any medium, provided the original work is properly cited.

\begin{abstract}
Background: Recent directions in the treatment of ADHD have involved both a broadening of pharmacological perspectives to include nor-adrenergic as well as dopaminergic agents. A review of animal and human studies of pharmacological and therapeutic directions in ADHD suggests that the DI receptor is a specific site for dopaminergic regulation of the PFC, but optimal levels of dopamine (DA) are required for beneficial effects on working memory. Animal and human studies indicate that the alpha-2A receptor is also important for prefrontal regulation, leaving open the question of the relative importance of these receptor sites. The therapeutic effects of ADHD medications in the prefrontal cortex have focused attention on the development of working memory capacity in ADHD.
\end{abstract}

Hypothesis: The actions of dopaminergic vs noradrenergic agents, currently available for the treatment of ADHD have overlapping, but different actions in the prefrontal cortex (PFC) and subcortical centers. While stimulants act on DI receptors in the dorsolateral prefrontal cortex, they also have effects on D2 receptors in the corpus striatum and may also have serotonergic effects at orbitofrontal areas. At therapeutic levels, dopamine (DA) stimulation (through DAT transporter inhibition) decreases noise level acting on subcortical D2 receptors, while NE stimulation (through alpha-2A agonists) increases signal by acting preferentially in the PFC possibly on DADI receptors. On the other hand, alpha-2A noradrenergic transmission is more limited to the prefrontal cortex (PFC), and thus less likely to have motor or stereotypic side effects, while alpha-2B and alpha-2C agonists may have wider cortical effects. The data suggest a possible hierarchy of specificity in the current medications used in the treatment of ADHD, with guanfacine likely to be most specific for the treatment of prefrontal attentional and working memory deficits. Stimulants may have broader effects on both vigilance and motor impulsivity, depending on dose levels, while atomoxetine may have effects on attention, anxiety, social affect, and sedation via noradrenergic transmission.

Tests of the hypothesis: At a theoretical level, the advent of possible specific alpha-2A noradrenergic therapies has posed the question of the role of working memory in ADHD. Head to head comparisons of stimulant and noradrenergic alpha- $2 \mathrm{~A}$, alpha-2B and alpha- $2 \mathrm{C}$ agonists, utilizing vigilance and affective measures should help to clarify pharmacological and therapeutic differences. 


\section{Background}

Recent directions in the treatment of ADHD have involved both a broadening of pharmacological perspectives to include nor-adrenergic as well as dopaminergic agents. This offers an opportunity, in conjunction with animal studies for a better understanding of the differential selectivity of these agents in the treatment of ADHD. A number of theories have been proposed for the effect of CNS stimulants on dopaminergic (DA) transmission in ADHD.

\section{Theories of cognitive processing}

Moghaddam and Homayoun [1] have described two distinct patterns of cerebral cognitive processing. A modular view is supported by animal and neurophysiological findings [2-4]. A second connectionist view emphasizes parallel distributed neural networks [5-7]. Contemporary approaches consider both types of processing relevant and generally assume that modular processing is a modification of parallel computational networks. The dorsolateral PFC (dlPFC) receives extensive innervations from the mediodorsal nucleus of the thalamus and sends prominent projections to dorsal striatum, nucleus accumbens and ventral tegmental area, allowing a key role in executive functions. On the other hand the orbitofrontal cortex (OFC) receives inputs from sensory associative cortices, particularly olfactory, gustatory, and visual areas, as well as hypothalamus and amygdala.

According to Volkow et al. [8], the processing of emotionally salient and behaviourally adaptive information may be at the core of response-reinforcement relations. The role of the frontal cortex, and specifically the anterior cingulate gyrus (CG), in emotional processing has been demonstrated in several imaging studies. Studies indicate an important integrative role for the OFC and CG in the analysis of information that carries an emotive, evaluative and in the long term, survival significance for an individual [8].

\section{Synaptic DA transmission}

Seeman and Madras [9] suggested that methylphenidate (MP) blocks the dopamine transporter (DAT), resulting in increased extracellular DA, activating autoreceptors and leading to an attenuation of DA release in response to phasic DA firing. On the other hand, a second hypothesis by Volkow et al suggests that the blocked DAT overcomes the inhibitory effects for activation of the autoreceptors, leading to a net effect of DA accumulation in the synapse, with amplification of DA signals resulting from tonic as well as phasic DA [8].

Grace has pointed out that by interfering with dopamine re-uptake, stimulants allow dopamine to escape the synaptic cleft, thereby depressing subsequent spike-depend- ent phasic dopamine release by increasing the tonic stimulation of the auto-receptor. Thus subcortical downregulation depends on presynaptic auto-inhibition through autoreceptors $[10,11]$. This mechanism is similar to that proposed by Seeman and Madras, who pointed out that stimulants raise extracellular levels of dopamine several-fold, but reduce the extent to which dopamine is released with nerve impulses, compared with the impulseassociated release in the absence of the drug. However at higher doses, stimulants are found to produce generalised stimulation of the nervous system, as a result of very high concentrations of extracellular dopamine at rest, and markedly increased release of dopamine with nerve impulses overcoming presynaptic inhibition of dopamine release [12].

Volkow et al. used positron emission tomography (PET) to demonstrate that extracellular DA increases in proportion to the level of DAT blockade, and the rate of DA release by cell firing. The latter increases were found to be greater when methylphenidate was given concomitantly with a salient rather than a neutral stimulus. The authors postulated that enhanced saliency and MP motivates the improved school performance observed with methylphenidate [8]. According to Volkow et al., symptoms of inattention have been mainly linked with striatum and cingulate gyrus, those of hyperactivity with striatum, and those of impulsivity with nucleus accumbens, while impairment in executive tasks is linked with the dorsolateral prefrontal cortex $[13,14]$.

\section{Dopamine and working memory}

Goldman-Rakic et al. investigated the pharmacological actions of drugs on neurons as they are engaged in cognitive processes in awake behaving animals [15]. They have shown that the 'memory fields' of the prefrontal cortex are modulated by neurotransmitters such as dopamine serotonin and gamma-amino-butyric acid (GABA) in different ways [16-18]. Goldman-Rakic et al. showed that the spatial tuning of prefrontal neurons engaged in spatial working memory was enhanced at moderate levels of occupancy, and reduced at both lower and higher levels of occupancy. The specificity of drug action on single cell activity was thought accounted for by the specific synaptic arrangement of $D_{1}$ receptors in spines that receive excitatory inputs from visual pathways carrying highly processed visuo-spatial information. The model postulated an optimal level of $D_{1}$ receptor occupancy for efficient physiological signalling and optimal performance [15].

Spatial working memory has been associated with the dorsolateral PFC, while the orbital and ventromedial PFC allow recognition and inhibition of emotional responses, important for appropriate social behaviour [19]. Goldman-Rakic and colleagues pointed out that a full under- 
standing of the functional capacity of even a single pyramidal cell requires knowledge not only of its biophysical properties but its circuitry and signalling mechanisms in vivo. Thus experimental depletion of dopamine in prefrontal areas of rhesus monkeys has been shown to produce impairments in working memory performance $[15,20]$. Furthermore Goldman-Rakic et al. [21] and Lidow et al. [22] have showed that the $\mathrm{D}_{1}$ family of dopamine receptors are at least 20-fold more abundant than $\mathrm{D}_{2}$ family of receptors in the PFC. The $\mathrm{D}_{1}$ receptor was also found to be in close proximity to putative glutamatergic axon terminals, giving rise asymmetric synapses on the same spine.

Muly et al. also studied the distribution of $\mathrm{D}_{1}$ receptor in GABAergic interneurons, and shown it is preferentially found in those subtypes of interneurons which provide the strongest inhibitory input to the perisomatic region of cortical pyramidal cells [23]. They suggested a circuit model to explain the biphasic action of $\mathrm{D}_{1}$ receptor stimulation on working memory performance and neuronal delay period firing, which focuses on the interactions between pyramidal and non-pyramidal neurons. The authors believe that $D_{1}$ receptor stimulation enhances excitatory transmission to both pyramidal cells and interneurons, but the enhancement is more effective on pyramidal cells, because of the closer contacts with dopaminergic axon terminals. On pyramidal neurons, the spine may act as a diffusion barrier, while on interneurons $\mathrm{D}_{1}$ receptor synapses are located on the shaft allowing for more diffusion of second messengers $[24,25]$.

\section{COMT and development}

In humans, the catechol-O-methyltransferase (COMT) gene contains a common variation in its coding sequence, which translates valine (Val) to methionine (Met). At room temperature the Met allele has one-fourth the enzyme activity of the Val allele. It is believed that COMT is important in the metabolism of DA in the prefrontal cortex (PFC) whereas the dopamine transporter (DAT) is more important in the striatum. The Val allele associated with high -activity COMT increases phasic and reduces tonic DA transmission sub-cortically and decreases DA concentrations cortically. This leads to an increase in $\mathrm{D}_{2}$ and a decrease in $\mathrm{D}_{1}$ receptor transmission; as a result there is decreased stability of neural networks, underlying working memory representations. The Met allele associated with low-activity COMT decreases phasic and increases tonic DA transmission sub-cortically, and increases DA concentrations cortically: this is associated with increased $D_{1}$ and decreased $D_{2}$ transmission in the PFC [26]. This increases the stability of networks mediating sustained working memory representations. A recent study found a small but significant relationship between Val ${ }^{158}$ Met genotype and executive function in healthy individuals but not in schizophrenia [27]. Thus the COMT gene (possibly in conjunction with other DA genes) may help predict DA function in the PFC. However, genetic studies in ADHD have shown limited association with ADHD [28]. This may be a developmental issue related to the late development of cortical PFC connections in adolescence, with late 'turning on' of the COMT gene [29].

According to Lewis and Gonzalez-Burgos, dendritic spines are the principal targets of excitatory synapses to pyramidal neurons [30]. Excitatory connections from the mediodorsal thalamus, the principal source of inputs to the dlPFC, synapse primarily on dendritic spines. Dendritic spine density on dlFPC layer 3 pyramidal neurons undergoes a substantial decline during adolescence in primates. Activity-dependent strengthening and pruning appears to underlie synapse stabilisation. It is suggested that functionally immature synapses may not be able to provide compensation for synaptic dysfunction prior to adolescence, because they have a very low AMPA receptor contribution, rendering them silent at the resting memory potential, and a relatively high probality of glutamate release, and thus subject to quick exhaustion of glutamate pools after repetitive activation. It is likely that a range of factors including labour-delivery, alcohol, nicotine and other stressors may affect the development of dlPFC circuitry. Dopamine is thought to exert a modulating influence on the dIPFC. It is thought that prefrontal pyramidal neurons may directly excite mesocortical DA neurons in the ventral mesencephalon and indirectly inhibit mesotriatal DA cells through activation of GABAergic neurons in mesencephalic cell nuclei [30]. Thus reduction in PFC cell activity leads to an excess of DA receptor activation at subcortical nuclei. In the primate dIPFC, D1 receptors are the most abundant DA receptor subtype, and mediate most of the cellular effects of DA in this subtype, and mediate most of the cellular effects of DA in this region [31]. Thus D1 receptors regulate sustained firing of dIPFC neurons during the delay phase of delayed-response tasks that require working memory $[32,33]$. DA neurons may also have an important role in gating information loaded into working memory buffers [34-37].

According to Lewis and Gonzalez-Burgos, COMT is mostly an intracellular cystolic protein [38]. Therefore, extracellular DA must be transported through the plasma membrane before becoming a substrate of COMT enzymatic activity, raising the question of potential interaction between genetic variants of COMT and the DA transporter. However, because COMT expression levels in DA neurons are relatively low $[39,40]$, the availability of DA to be inactivated by COMT is dependent on DA transport through the membrane of cortical cells that express higher levels of COMT (e.g. post-synaptic neurons or glia), and 
that may express non-specific transporters with the ability to uptake DA. It is thus important, according to the authors, to note that COMT metabolises norepinephrine, which heavily innervates the primate dlPFC [41] and influences working memory function [42].

Lewis and Gonzalez-Burgos [30] point out that although the interneuron depolarization and the increase in inhibitory currents produced by DA suggests net inhibitory effects in the primate dIPFC, DA also changes the response of pyramidal neurons to excitatory currents with a delayed time course [32] and is consistent with other delayed D1 receptor-mediated effects [36]. This may partly account for the inverted-U dose-response effect on dlPFC firing, though these effects may be complex [43] Low levels of DA receptor stimulation appear to selectively increase the firing of neurons that are tuned to preferred stimuli during tasks that require working memory [16].

\section{Developmental hypothesis}

While an association has been proposed between DRD1 and schizophrenia, most genetic association studies in ADHD have been directed towards the dopamine transporter, DAT1 and the DRD4 receptor. An influential developmental hypothesis, the Dynamic Developmental Theory (DDT) suggested that the dopaminergic system is hypoactive in ADHD, and explains the behavioural changes in terms of altered reinforcement and extinction processes [44]. This leaves open the question of the role of working memory in ADHD, presumably related to deficits in the prefrontal DRD1 system. The present developmental hypothesis suggests early deficits in PFC connectivity, in both young children and in ADHD. In this case stimulant medications may 'remediate' a deficient working memory system, as suggested in neuropsychological studies of vigilance $[45,46]$.

\section{Noradrenergic mechanisms}

The above 'vigilance/working memory' hypothesis also draws attention to the noradrenergic (NA) system. Optimal prefrontal cortex function is thought to require optimally functioning noradrenergic and dopaminergic input to the prefrontal cortex $[47,48]$. A relatively recent approach to the treatment of ADHD has been the finding of beneficial effects from alpha-noradrenergic agents such as atomoxetine and guanfacine. The molecular genetic basis for the use of noradrenergic agents has been best reviewed by Arnsten et al. [49]. They point out that it has been appreciated for some time that dopamine (DA) is necessary for proper prefrontal cortex (PFC) function, but more recently a role for noradrenergic transmission has been appreciated. According to Arnsten et al., the role of the $\mathrm{D}_{1}$ receptor family in the regulation of PFC function has received particular focus, particularly as $D_{1}$ receptors are found in high concentration in the PFC on dendritic spines. This allows DA to modulate incoming information to PFC pyramidal cells [50,51]. On the other hand, supra-normal DA stimulation may impair PFC function, providing an inverted-U effect. For example, GoldmanRakic et al., found that the D1 message and protein in the cortex of rhesus monkeys was down-regulated by chronic neuroleptic treatment, which both down-regulated D1 receptors and produced impairments in working memory performance [23].

According to Arnsten et al. electrophysiological recordings of PFC neurons in monkeys performing working memory tasks, have shown that PFC neurons are able to hold modality-specific information "on-line" over a delay period and use this representational information to guide behaviour in the absence of environmental cues. The delay-related firing is thought to arise from feed-forward microcircuits within the PFC, as cells with shared properties interconnect [52]. Arnsten et al. suggest there are no drugs that distinguish between $D_{1}$ and $D_{5}$ receptors, and moderate levels of $D_{1} / D_{5}$ receptor stimulation suppress delay-related firing for non-preferred spatial directions, and thus enhance spatial tuning. The authors point out that while limited studies have been done in humans, due to the lack of selective $D_{1} / D_{5}$ compounds available for human use, studies with non-selective compounds suggest that an "inverted-U" response may be evident in humans as well as animals. They suggest that compounds that prefer $D_{1}$ receptors may be more helpful than $D_{2}$ agonists in improving verbal memory [52].

\section{Alpha-2A receptor}

According to Arnsten [53], relatively high doses of alpha2 agonists appear to have beneficial effects on cognitive function, although these effects may be eroded by emerging sedative and hypotensive effects. However, Arnsten et al. [52] and Arnsten and Leslie [54] have shown that the ability of alpha-2 agonists to improve PFC function without side effects was found to correspond with selectivity for the alpha-2A receptor site. A comparison between the three NA alpha-2 receptors guanfacine, clonidine and BHT showed guanfacine had better selectivity than clonidine, which is more selective than BHT 920. Thus open trials [55-57] have shown beneficial effects of guanfacine, including improved performance on the Continuous Performance Task [58]. Arnsten suggests that NA-alpha-1 and NA-alpha-2 receptors may have opposing effects in the PFC, and that alpha-2 mechanisms may predominate when basal NA release is moderate, as in normal attentive wakening, and alpha- 1 mechanisms may predominate under conditions of stress with higher levels of NA release. Thus alpha-2 agonists such as guanfacine may protect PFC cognitive function during stress by preventing excessive NA or DA release in the PFC [53]. 
Easton et al. utilised phMRI BOLD (magnetic resonance imaging) contrast to image the blood oxygenation level dependant response in rat brain regions following administration of guanfacine [59]. They postulated that activation of alpha-2 receptors in the dorsolateral PFC by an agonist such as guanfacine might facilitate PFC neuronal activity and in turn exert an inhibitory influence on other cortical areas (such as premotor and motor areas) and/or subcortical structures (such as the striatum) that are involved in the control of locomotion. Time-course analyses of saline vs guanfacine effects were carried out, using both fixed and random effect analyses. Random effect analysis showed that guanfacine produced positive BOLD responses in frontal areas, including the frontal association and secondary motor cortex and prelimbic region of the PFC. This is consistent with single-photon emission computed tomography (SPECT) evidence, which shows improved cognitive performance and increased rCBF (cerebral blood flow) values in the dorsolateral PFC following guanfacine administration to young adult rhesus monkeys, and with human positron emission tomography (PET) data showing increased regional cerebral blood flow in frontal lobes following guanfacine administration. Positive BOLD changes also occurred in the dentate gyrus and $\mathrm{CA}_{1}$. Guanfacine produced widespread negative BOLD effects in the caudate, putamen, nucleus accumbens and entorhinal cortex, suggesting decreased dopaminergic neuronal function in this area.

Easton et al. interpreted their data as suggesting that guanfacine acts on the prefrontal cortex (probably post-synaptically at alpha- 2 receptors) to increase cognitive and associated functions, known to be dysfunctional in ADHD sufferers, and also helps in the regulation of locomotor activity via inhibitory control of subcortical brain regions, particularly the caudate putamen and nucleus accumbens [59]. Thus guanfacine appeared to have the ability to 'turn down' striatal activity, possibly of benefit in the treatment of motoric hyperactivity. The investigators also demonstrated an intense positive BOLD effect in the lateral hypothalamic area, which is strongly associated with feeding behaviour, perhaps a basis of appetite or gastrointestinal side effects $[60,61]$.

According to Easton et al. the alpha-2A adrenergic receptor subtype appears to be the site of action of the beneficial clinical effects of alpha-2A agonists on the prefrontal cortex (PFC) [59]. While these receptors are localized both pre- and post- synaptically, some lines of evidence are thought to suggest that their site of action is post-synaptic in the PFC [62]. Thus, guanfacine has been shown to dosedependently prevent deficits of spatial working memory, suggesting a role in cognitive deficits associated with NMDA receptor hypofunction $[63,64]$. Application of the $D_{1}$ receptor agonist SKF81297 has been shown to cause a prominent increase of steady-state NMDA-evoked current in acutely isolated PFC pyramidal neurons, and up-regulation of NMDA receptor activity by dopamine $\mathrm{D}_{1}$ receptors suggests reciprocal interactions between $D_{1}$ and NMDA receptors [65].

Arnsten et al. suggest that stimulants act to enhance the release of and/or inhibit the reuptake of both DA and NE (norepinephrine) [54]. Arnsten and Dudley [66] have shown that the PFC-enhancing effects of methylphenidate are prevented by blockade of either NE alpha-2 or DAD1 receptors, suggesting that stimulants facilitate endogenous stimulation of $D_{1}$ and alpha-2A receptors in the PFC. It is thought to increase delay-related firing and strengthens the functional connectivity of microcircuits in the PFC. In children, Scahill et al. found that immediate release guanfacine was rated significantly better than placebo by teacher-rated ADHD (37\% vs $8 \%$ ) and subjects performed significantly better on a Continuous Performance Test [67].

Arnsten et al. also suggest that as with DA, moderate levels of NE are critical for proper PFC function [54]. They suggest that the majority of alpha-2 receptors are localised postsynaptically to NE terminals, and that blockade of alpha-2 receptors in the PFC of monkeys erodes delayrelated cell-firing and recreates all the symptoms of ADHD, with poor impulse control, impaired working memory with underlying distractibility.

Wang et al. have shown that spatial working memory is maintained by spatially tuned recurrent excitation within networks of prefrontal cortical neurons [68]. They investigated monkeys performing on an oculomotor spatial delayed response, which required monkeys to make a memory-guided saccade to a visuo-spatial target. Neurons recorded from area 46 of the dorsolateral PFC were isolated and subjected to iontophonetic application of pharmacological agents. Intra-PFC administration of guanfacine was shown to significantly enhance delayrelated activity for the $180^{\circ}$ location (preferred direction) in 28 out of 35 cases. Studies indicated that suppression of cyclic AMP impaired WM performance.

Wang et al suggest that CAMP (cyclic AMP) has powerful influences on Hyperpolarisation Activated Cyclic Nucleotide-gated (HCN) channels that pass on h current when opened [68]. They are localised on distal pyramidal dendrites and according to the authors, are co-expressed with the alpha-2A adrenoreceptor, thus providing a potent substratum for functional integration in the primate PFC. In electrophysiological studies with alpha-2A adrenoreceptor stimulation or cAMP inhibition, HCN channel blockade enhanced spatially tuned delay-related firing of PFC neurons. Exposure to uncontrollable stress via excessive 
catecholamine release, high levels of $\mathrm{D}_{1}$ receptor stimulation, or by activating CAMP, has been shown to impair working memory. Under these conditions, the PFC is functionally disconnected rendering it "decorticate". The process may be exacerbated in patients with aberrant genes that regulate CAMP signaling e.g. COMT [69]. This co-localisation of cAMP, HCN channels and $\mathrm{D}_{1}$ excess stimulation effects may help to explain the cross-talk between DA and NE receptors in the PFC discussed below.

Vijayraghavan et al. showed that dopamine $\mathrm{D}_{1}$ receptor stimulation in PFC produced an 'inverted-U' doseresponse, whereby either too little or too much $\mathrm{D}_{1}$ receptor stimulation impaired spatial working memory [69]. This response has been observed across species, including genetic linkages with human cognitive abilities, PFC activation states and DA synthesis. According to the authors the cellular basis for the inverted $U$ has long been sought, with in vitro intracellular recordings supporting a variety of potential mechanisms. Their study demonstrated that the $\mathrm{D}_{1}$ receptor agonist inverted- $U$ response was observed in PFC neurons of behaving monkeys: low levels of $D_{1}$ receptor stimulation enhanced spatial tuning by suppressing responses to non-preferred directions, whereas high levels reduced delay-related firing for all directions, eroding tuning. These actions of $D_{1}$ receptor stimulation were mediated in monkeys and rats by cyclic AMP intracellular signaling. The evidence for an inverted-U at the cellular level in behaving animals promised to bridge in vitro molecular analyses with human cognitive experience.

Arnsten et al. have described three different subtypes of alpha-2 adrenoreceptors in humans, the alpha-2A alpha2B and alpha-2C subtypes [54]. The alpha-2A and alpha2C subtypes are widely distributed in the brain, including the $\mathrm{PFC}$, the alpha- $2 \mathrm{~B}$ receptor is most concentrated in the thalamus. Guanfacine is thought to be the most selective agonist available for the alpha-2A subtype [70]. On the other hand the sedating effects of clonidine are thought to involve the thalamus, basal forebrain and other alpha-2B and alpha-2C effects. Atomoxetine, which also has sedating effects in some children, may also have alpha-2B and/ or alpha-2C effects [48].

A recent study by Chamberlain et al. suggested that NE is more sensitive in modulating lateral compared to orbital PFC functioning [71]. They showed that atomoxetine (60 mg single dose) improved response inhibition on a stopsignal task, but had no effect on a task requiring probabilistic learning. On the other hand administration of citalopram (30 mg single dose) impaired probabilistic learning with no effect on response inhibition. The authors concluded that finding that atomoxetine improved response inhibition in healthy volunteers implicated ascending noradrenergic systems in its control, whereas the role of 5-HT in probabilistic learning might operate according to an inverted-U function.

\section{Clinical implications}

While clinical studies of guanfacine are limited, despite some promising results, there has been considerable interest in the use of atomoxetine. Despite some encouraging trial results, [72] anecdotal clinical reports suggest limited success in some children, and there have also be concerns about suicidal ideation in a small number of patients [73]. This raises the question of the pharmacological actions of atomoxetine, which also increases extrasynaptic levels of $\mathrm{NE}$ and DA in the PFC.

The selectivity of atomoxetine for NE effects, was investigated by Bymaster et al., utilising radioligands and microdialysis studies [74]. They showed that atomoxetine increased extracellular levels of NE in the prefrontal cortex 3-fold, but did not alter 5-HT levels. Atomoxetine also increased DA concentrations in the PFC 3-fold but did not alter DA in nucleus accumbens or striatum. In contrast methylphenidate increased DA and NE equally in PFC, but also increased DA in striatum and nucleus accumbens to the same level. The authors suggest that atomoxetine is thus less likely to have motoric or abuse liability.

Arnsten and Li suggest that noradrenergic transmission has a vital beneficial effect on PFC function, particularly via postsynaptic alpha-2-adrenoreceptors. Alpha -2 agonists such as guanfacine have been shown to improve working memory performance in monkeys after direct infusion into the dorsolateral PFC [75]. Blockade of alpha -2 receptors with yohimbine infusion was shown to weaken working memory [76], and in addition to induce motor hyperactivity [77]. Arnsten and Li have pointed out that the PFC guides behaviour, thought and affect using working memory, and that these processes are the basis of executive functions, including regulation of attention, planning and impulse control [75]. PFC function is thought to be fundamental in ADHD $[48,49]$. As outlined above, stimulation of the $\mathrm{D}_{1}$ receptor within optimal levels improves working memory performance, while higher levels may erode performance $[78,79]$. The role of $\mathrm{D}_{2}, \mathrm{D}_{3}$ and $\mathrm{D}_{4}$ receptors in the PFC are, according to Arnsten and Li less well understood, though it is of interest that NA has high affinity for the $\mathrm{D}_{4}$ receptor, which may be considered a catecholamine rather than a DA receptor [75].

Interestingly, while it has been accepted in the past that the beneficial effect effects of stimulant medication were mediated by DA transmission, Arnsten and Li suggest that performance on PFC tasks in rats and mice on low oral doses of methylphenidate may be mediated in part by the alpha-2 adrenoreceptor [75]. Thus stimulants, atomoxetine and guanfacine may exert therapeutic actions via $D_{1}$ 
and alpha-2A receptor mechanisms, but under conditions of stress, guanfacine may be more protective [80], given that high doses of stimulants may impair cognition and induce perseverative or restricted thinking [81].

\section{Receptor specificity}

Arnsten describes the PFC as using representational knowledge, i.e. to guide overt responses as well as allowing inhibition of inappropriate behaviours by gating the processing of irrelevant stimuli. Studies in rats have shown that low oral doses of methylphenidate that produce plasma drug levels similar to therapeutic doses in humans, also improve PFC function, dependant on both dopamine $\mathrm{D}_{1}$ and NE- alpha-2 receptor stimulation [82].

Acccording to Arnsten, the enhancing effects of alpha-2A agonists are most likely mediated through G-mediated suppression of CAMP intracellular signaling. Blocking alpha- 2 receptors in monkey PFC with yohimbine reduces delay-related cell firing and impairs working memory, as well as impulse control, recreating the profile of ADHD. In contrast excessive stimulants produce cognitive inflexibility through alpha 1, beta and high D1 stimulation [66].

It is still somewhat unclear whether DA effects in the PFC are exerted primarily through the DAD1 receptor, or alpha-2A receptor. Cornil et al have shown that dopamine activates noradrenergic receptors in the quail preoptic area [83]. They found that DA-induced inhibitions/excitations were not blocked by selective dopaminergic receptor antagonists, but were suppressed by selective alphanoradrenergic antagonists (yohimbine/prasozin). While the mechanism of the cross-talk between DA and NE receptors was unclear, the relatively similar structure of DA and NE could potentially explain the binding of both amines to the two receptor subtypes, as could co-localisation of CAMP, HCN channels and alpha-2A adrenoreceptor [68]. Studies of transgenic mice demonstrated that the transporters for NE and DA lacked specificity, so that in the prefrontal cortex, DA was mainly taken up by the NE transporter [84]. The mechanisms and specificity in human therapeutics remains an intriguing problem whose solution offers more targeted understanding of future treatments.

\section{Conclusion}

The above understandings have given rise to newer treatment approaches. In particular there has been increased interest in the efficacy of both non-stimulant and longacting agents. A variety of extended release dopaminergic agents are being or have been produced by pharmaceutical companies but so far none have been selective for the PFC alone, and may also be subject to motor and stereotypic effects at striatal level. Taken together the data seems to suggest differences in specificity in the current medica- tions used in the treatment of ADHD, with guanfacine likely to be most specific for the treatment of attentional deficits, while stimulants may have broader effects on both vigilance and motor impulsivity depending on dose levels. Atomoxetine has effects on attention, social affect, anxiety and sedation via noradrenergic systems. Head to head comparisons utilizing both vigilance and affective measures, such as facial recognition may further elucidate differential effects. At a theoretical level, the advent of specific noradrenergic therapies such as guanfacine, raises the question of the role of working memory in the treatment of ADHD. Also suggested, is a possible aetiological role of developmental deficit or delay, at the prefrontal cortical level, in ADHD.

\section{Competing interests}

The author declares that she has no competing interests.

\section{Abreviations}

D1 Dopamine D1 receptor: PFC Prefrontal cortex; OFC Orbitofrontal cortex;

DAT Dopamine transporter; COMT Catechol-O-methyltransferase;

NA Noradrenergic; NE Norepinephrine;

MRI Magnetic Resonance Imaging; BOLD Blood oxygen level dependent;

SPECT Single-photon emission computed tomography; NMDA N-methyl D-aspartate;

CAMP Cyclic AMP; HCN Hyperpolarisation Activated Cyclic Nucleotide-gated

\section{References}

I. Moghaddam B, Homayoun : Divergent plasticity of prefrontal cortex networks. Neuropsychopharm 2008, 33:42-55.

2. Mishkin M, Pribram K: Analysis of the effects of frontal lesions in monkeys, I. J Comp Physiol Psychol 1955, 48:492-495.

3. Goldman P, Rosvold $\mathrm{H}$ : Localization of function within the dorsolateral prefrontal cortex of the rhesus monkey. Exp Neurol 1970, 27:291-304.

4. Stuss DT, Benson DF: Neuropsychological studies of the frontal lobes. Psychol Bull 1999, I I 7:728-737.

5. Edelman GM, Mountcastle VB: The Mindful Brain Plenum Press: New York; 1978.

6. Goldman-Rakic PS: Topography of cognition: parallel distributed networks in primate association cortex. Annu Rev Neurosci 1988, II:137-156.

7. Fuster JM: Cortex and the Mind: Unifying Cognition Oxford University Press, New York; 2003.

8. Volkow ND, Wang G-J, Fowler JS, Yu-Shin D: Imaging the effects of methylphenidate on brain dopamine: New model on its therapeutic actions for Attention-Deficit/Hyperactivity Disorder. Biol Psychiatry 2005, 57:1410-1415.

9. Seeman P, Madras BK: Anti-hyperactivity medication: methylphenidate and amphetamine. Mol Psychiatry 1998, 3:386-396.

10. Grace AA: The tonic/phasic model of dopamine system regulation: its relevance for understanding how stimulant abuse 
can alter basal ganglia function. Drug Alc Dependance 1995, 37:III-129.

11. Grace AA: Phasic versus tonic dopamine release and the modulation of dopamine system responsivity: A hypothesis for the etiology of schizophrenia. Neuroscience 1991, 41:I-24.

12. Seeman P, Madras B: Methylphenidate elevates resting dopamine which lowers the impulse-triggered release of dopamine: a hypothesis. Behav Brain Res 2002, 130:79-83.

13. Castellanos FX: Toward a pathophysiology of attention-deficit/ hyperactivity disorder. Clin Pediatr (Phila) 1997, 36:38I-393.

14. Dinn WM, Robbins NC, Harris CL: Adult attention-deficit/hyperactivity disorder: Neuropsychological correlates and clinical presentation. Brain Cogn 200I, 46: II4-I2I.

15. Goldman-Rakic PS, Muly EC III, Williams GV: $D_{1}$ receptors in prefrontal cells and circuits. Brain Res Rev 2000, 3I:295-30I.

16. Williams GV, Goldman-Rakic P: Modulation of memory fields by dopamine DI receptors in prefrontal cortex. Nature 1995, 376:572-575.

17. Williams GV, Rao SG, Goldman-Rakic PS: The influence of 5-HT receptors on local circuit function in primate prefrontal cortex. Soc Neurosci Abstr 1999, 25:355. 13.

18. Rao SG, Williams GV, Goldman-Rakic PS: Destruction and creation of spatial tuning by disinhibition: GABAA Blockade of prefrontal cortical neurons engaged by working memory. J Neurosci 2000, 20:485-494.

19. Anderson SW, Bechara A, Damasio H, Tranel D, Damasio AR: Impairment of social and moral behavior related to early damage in human prefrontal cortex. Nat Neurosci 1999, 2: $1032-1037$.

20. Brozoski T, Brown RM, Rosvold HE, Goldman PS: Cognitive deficit caused by regional depletion of dopamine in prefrontal cortex of rhesus monkey. Science 1979, 205:929-932.

21. Goldman-Rakic PS, Lidow MS, Gallagher DW: Overlap of dopaminergic, adrenergic, and serotonergic receptors and complementarity of their subtypes in primate prefrontal cortex. J Neurosci 1990, 10:2125-2138.

22. Lidow MS, Goldman-Rakic PS, Gallagher DV, Rakic P: Distribution of dopaminergic receptors in the primate cerebral cortex: Quantitative autoradiographic analysis using [3H] raclopride, $[3 \mathrm{H}]$ spiperone and $[3 \mathrm{H}] \mathrm{SCH} 23390$. Neurosci 199I, 40:657-67I.

23. Muly EC III, Szigeti K, Goldman-Rakic PS: DI receptor in interneurons of macque prefrontal cortex: distribution and subcellular localization. J Neurosci 1998, I 8: I0553-10565.

24. Murphy BL, Arnsten AFT, Goldman-Rakic PS, Roth RH: Increased dopamine turnover in the prefrontal cortex impairs spatial working memory performance. Proc Natl Acad Sci 1996, 93:1325-1329.

25. Zart J, Taylor JR, Mathew RG, Arnsten AFT: Supranormal stimulation of $D_{1}$ receptors in the rodent prefrontal cortex impairs spatial working memory performance. J Neurosci 1997, 1 7:8528-8535.

26. Bilder RM, Volavka J, Lachman HM, Grace AA: The Catechol-OMethyltransferase polymorphism: Relations to the TonicPhasic dopamine hypothesis and neuropsychiatric phenotypes. Neuropsychopharm 2004, 29:1943-1961.

27. Barnett JH, Jones PB, Robbins TW, Müller U: Effects of the catechol-O-methyltransferase Vall 58Met polymorphism on executive function: a meta-analysis of the Wisconsin Card Sort Test in schizophrenia and healthy controls. Mol Psychiatry 2007, I 2:502-509.

28. Faraone SV, Perlis RH, Doyle AE, Smoller JW, Goralninick J], Homgren MA, Sklar K: Molecular genetics of Attention-Deficit/ Hyperactivity Disorder. Mol Psychiatry 2005, 57:13|3-|323.

29. Levy F: What do dopamine transporter and catechol-o-methyltransferase tell us about attention deficit-hyperactivity disorder? Pharmacogenomic implications. Aust N Z J Psychiatry 2007, 4I: 10-16.

30. Lewis DA, Gonzalez-Burgos G: Neuroplasticity of neocortical circuits in Scizophrenia. Neuropsychopharmacol Re 2008, 33:14I-165.

31. Lewis DA, Gonzalez-Burgos G: Physiologically based treatment interventions in schizophrenia. Nat Med 2006, 12:1016-1022

32. Gonzalez-Burgos G, Kroner S, Krimer LS, Seamans JK, Urban NN, Henze DA, et al.: Dopamine modulation of neuronal function in the monkey prefrontal cortex. Physiol Behav 2002, 77:537-543.

33. Sawaguchi $\mathrm{T}$ : The effects of dopamine and its antagonists on directional delay-period activity of prefrontal neurons in monkeys during an oculomotor delayed-response task. Neurosci Res 200I, 4 I:III5-128.

34. Williams GV, Goldman-Rakic PS: Modulation of memory fields by dopamine DI receptors in prefrontal cortex. Nature 1995, 376:572-575

35. Rotaru DC, Lewis DA, Gonzalez-Burgos G: Dopamine DI receptor activation regulates sodium channel-dependent EPSP amplification in rat prefrontal cortex pyramidal neurons. Physiol 2007, 58 I:98-1000.

36. Seamans JK, Yang CR: The principal features and mechanisms of dopamine modulation in the prefrontal cortex. Prog Neurobiol 2004, 74: I-58.

37. Yang CR, Seamans JK, Gorelova N: Developing a neuronal model for the pathophysiology of schizophrenia based on the nature of electrophysiological actions of dopamine in the prefrontal cortex. Neuropsychopharmacol 1999, 21:161-194.

38. Tunbridge EM, Weinberger DR, Harrison PJ: A novel protein isoform of catechol-O-methyltransferase (COMT): brain expression analysis in schizophrenia and bipolar disorder and effect of Vall58Met genotype. Mol Psychiatry 2006, I I:533 I-5335.

39. Kastner A, Anglade P, Bounaix C, Damier P, Javoy-Agid F, Bromet N, et al.: Immunohistological study of catechol-O-methyltransferase in the human mesostriatal system. Neuroscience 1994, 62:449-457.

40. Lundstrom K, Tenhunen J, Tilgmann C, Karhunen T, Panula P, Ulmanen I: Cloning, expression and structure of catechol-Omethyltransferase. Biochim Biophys 1995, I 25 I:I-10.

4I. Lewis DA, Morrison JH: noradrenergic innervation of monkey prefrontal cortex: a dopamine-beta-hydroxylase immunohistochemical study. J Comp Neurol 1989, 282: I 19-138.

42. Arnsten AFT, Goldman-Rakic PS: Alpha (2)-adrenergic mechanisms in prefrontal cortex associated with cognitive decline in aged nonhuman primates. Science 1985, 230: I273-1276.

43. Vijayraghavan S, Wang M, Birnbaum SG, Williams GV, Arnsten AF Inverted-U dopamine $D I$ receptor actions on prefrontal neurons engaged in working memory. Nat Neurosci 2007, 10:376-384

44. Sagvolden T, Johansen EB, Aase H, Russell VA: A dynamic developmental theory of attention-deficit/hyperactivity disorder (ADHD) predominantly hyperactive impulsive and combined subtypes. Behav Brain Sci 2005, 28:397-468.

45. Levy F, Hobbes G: The action of stimulant medication in Attention Deficit Hyperactive children. J Amer Acad Child Adolesc Psychiatry 1988, 27:802-805.

46. Bellgrove MA, Hawi Z, Gill M, Robertson IH: The cognitive genetics of attention deficit hyperactivity disorder (ADHD): Sustained attention as a candidate phenotype. Cortex 2006, 42:838-845.

47. Russell VA: Hypodopaminergic and hypernoradrenergic activity in prefrontal cortex slices of an animal model for attention-deficit hyperactivity disorder .-. the spontaneously hypertensive rat. Behav Brain Res 2001, 130:191-196.

48. Solanto MV: Neuropharmacological mechanisms of stimulant drug action in attention-deficit hyperactivity disorder: A review and integration. Behav Brain Res 1998, 94:127-152.

49. Arnsten AF, Scahill L, Findling RL: Alpha-2 adrenergic receptor agonists for the treatment of Attention-Deficit/Hyperactivity Disorder: Emerging concepts from new data. J Child Adolesc Psychopharm 2007, I7:393-406.

50. Goldman-Rakic PS: Cellular basis of working memory. Neuron 1995, 14:477-485.

5I. Kimberg M, Farah MJ: Effects of bromocriptine on human subjects depend on working memory capacity. Neuroreport 1997, 8:358I-3585.

52. Arnsten AFT, Cai JX, Goldman-Rakic PS: The alpha-2 adrenergic agonist guanfacine improves memory in aged monkeys without sedative or hypotensive side effects. J Neurosci 1998, 8:4287-4298

53. Arnsten AFT: Catecholamine regulation of the prefrontal cortex. J Psychopharmacol 1997, I I:151-162. 
54. Arnsten FT, Leslie FM: Behavioral and receptor binding analysis of the alpha-2 adrenergic agonist. UK-I 4304 (5 bromo-6 [2imidazoline-2-yl amino] quinoxaline): Evidence for cognitive enhancement at an $\alpha_{-2}$ adrenoreceptor subtype. Neuropharmacol 1991, 30:1279-1289.

55. Hunt RD, Arnsten AF, Asbell MD: An open trial of guanfacine in the treatment of attention-deficit hyperactivity disorder. J Amer Acad Child Adolesc Psychiatry 1995, 34:50-54.

56. Horrigan JP, Barnhill LJ: Guanfacine for treatment of attentiondeficit hyperactivity disorder in boys. J Child Adolesc Psychopharmacol 1995, 5:215-223.

57. Cohn LM, Caliendo GC: Guanfacine use in children with attention deficit hyperactivity disorder. Ann Pharmacotherapy 1997, 31:918-919.

58. Chappell PB, Riddle MA, Scahill L, Lynch KA, Schultz R, Arnsten A, et al.: Guanfacine treatment of comorbid attention deficit hyperactivity disorder and Tourette's syndrome: Preliminary clinical experience. J Amer Acad Child Adolesc Psychiatry 1995, 34: I I40-II46.

59. Easton N, Shah YB, Marshall FH, Fone KC, Marsden CA: Guanfacine produces differential effects in frontal cortex compared with striatum: assessed by phMRI BOLD contrast. Psychopharmacol 2006, 189:369-385.

60. Rufffin MP, Caulliez R, Nicolaidis S: Parallel metabolic and feeding responses to lateral hypothalamic stimulation. Brain Res 1995, 700: $121-128$.

61. Bernardis LL, Bellinger LL: The lateral hypothalamic area revisited: ingestive behavior. Neurosci BiobehavRev 1996, 20:189-287.

62. Cai JX, Ma YY, Xu L, Hu XT: Reserpine impairs spatial working memory performance in monkeys: reversal by the alpha-2 adrenergic agonist clonidine. Brain Res 1993, 614:191-196.

63. Avery RA, Franowicz JS, Studholme C, van Dyck CH, Arnsten AF: The alpha-2-A-adrenoreceptor agonist, guanfacine, increases regional cerebral blood flow in dorsolateral prefrontal cortex of monkeys performing a spatial working memory task. Neuropsychopharmacol 2000, 23:240-249.

64. Swartz BE, Kovalik E, Thomas K, Torgeson D, Mandelkern MA: The effects of an alpha-2 adrenergic agonist, guanfacine, on rCBF in human cortex in normal controls and subjects with focal epilepsy. Neuropsychopharmacol 2000, 23:263-275.

65. Chen G, Greengard P, Yan Z: Potentiation of NMDA receptor currents by dopamine $D$, receptors in prefrontal cortex. PNAS 2004, 101:2596-2600.

66. Arnsten AFT, Dudley AG: Methylphenidate improves prefrontal cortical cognitive function through $\alpha 2$ adrenoceptor and dopamine DI receptor actions: Relevance to therapeutic effects in Attention Deficit Hyperactivity Disorder. Behavioral and Brain Functions 2005, I:2. doi:10.1 I86/I744-908I-I-2

67. Scahill L, Chappel PB, Kim YS, Schulz RT, Katsovich L, Shepherd E, Arnsten AFT, Cohen DJ, Leckman JF: Guanfacine in the treatment of children with tic disorders and ADHD: A placebocontrolled study. Am J Psychiatry 200I, I 58:1067-1074.

68. Wang M, Ramos BP, Paspalas CD, Shu Y, Simen A, Duque A, Ayraghavan S, Brennan A, Dudley A, Nou E, Mazer JA, McCormick DA, Arnsten AFT: $\alpha 2 A$ - adrenoreceptors strengthen working memory networks by inhibiting cAMP-HCN channel signalling in prefrontal cortex. Cell 2007, 129:397-4I0.

69. Vijayraghavan S, Wang M, Birnbaum SG, Williams GV, Arnsten AFT: Inverted-U dopamine DI receptor actions on prefrontal neurons engaged in working memory. Nature Neuroscience 2007, 10:376-384.

70. Franowicz JS, Kessler L, Daily-Borja CM, Kobilka BK, Limbird LE, Arnsten AFT: Mutation of the alpha-2A adrenoreceptor impairs working memory performance and annuls cognitive enhancement by guanfacine. Neurosci 2002, 22:877I-8777.

7I. Chamberlain SR, Muller U, Robbins TW, Sahakian B: Neuropharmacological modulation of cognition (degenerative and cognitive diseases). Current Opin Neurol 2006, 19:607-6I2.

72. Michelson D, Faires D, Wernicke J, Kelsey D, Kendrick K, Sallee R, Spenser T: Atomoxetine in the treatment of children and adolescents with Attention-Deficit/Hyperactivity Disorder: A randomised placebo-controlled dose response study. Pediatr 200I, 108:E83.

73. Bangs MS, Tauscher-Wisniewski S, Polzer J, et al.: Meta-analysis of suicide-related events in atomoxetine-treated patients. Pre- sented at the 52nd Annual Meeting of the American Academy of Child and Adolescent Psychiatry: Toronto, Ontario Canada; 2005.

74. Bymaster FP, Katner JS, Nelson DL, Hemrick-Luecke SK, Threlkeld PG, Hellingenstein JH, Morin JH, Michelle S, Gehlert DR, Perry KW: Atomoxetine increases extracellular levels of norepinephrine and dopamine in prefrontal cortex of rat: a potential mechanism for efficacy in attention deficit/hyperactivity disorder. Neuropsychopharm 2002, 27:699-7II.

75. Arnsten AFT, Li Bao-Ming: Neurobiology of executive functions: Catecholamine influences on prefrontal cortical functions. Biol Psychiatry 2005, 57:1377-1384.

76. Li B, Mei Z-T: Delayed response deficit induced by local injection of the alpha-2 adrenergic antagonist yohimbine into the dorsolateral prefrontal cortex in young adult monkeys. Behav Neural Biol 1994, 62:134-139.

77. Ma C-L, Arnsten AFT, Li B-M: Locomotor hyperactivity induced by blockade of prefrontal cortical alpha-2-adrenoreceptors in monkeys. Biol Psychiat 2005, 57:192-195.

78. Sawaguchi T, Goldman-Rakic PS: The role of $D_{1}$-dopamine receptors in working memory: Local injections of dopamine antagonists into the prefrontal cortex of rhesus monkeys performing an oculomotor delayed response task. J Neurophysiol 1994, 71:35I-358.

79. Murphy BL, Arnsten AFT, Goldman-Rakic PS, Roth RH: dopamine turnover in the prefrontal cortex impairs spatial working memory performance in rats and monkeys. Proc Nat Acad Sci USA 1996, 93:1325-1329.

80. Taylor FB, Russo J: Comparing guanfacine and dextroamphetamine for the treatment of adult Attention Deficit-Hyperactivity Disorder. J Clin Psychopharmacol 1999, 21:223-228.

8I. Chamberlain SR, Muller U, Blackwell AD, Clark L, Robbins TW, Sahakian BJ: Neurochemical modulation of response inhibition and probalistic learning in humans. Science 2006, 311 : $861-863$.

82. Arnsten AFT: Fundamentals of Attention-Deficit/Hyperactivity Disorder: Circuits and pathways. J Clin Psychiatry 2006, 67(suppl 8):7-12.

83. Cornil CA, Balthazart J, Motte P, Massote L, Seutin V: Dopamine activates noradrenergic receptors in the preoptic area. J Neurosci 2002, 22:9320-9330.

84. Moron JA, Brockington A, Wise RA, Rocha BA, Hope BT: Dopamine uptake through norepinephrine transporter in brain regions with low levels of the dopamine transporter: evidence from knockout mouse lines. J Neurosci 2002, 22:389-395.
Publish with BioMed Central and every scientist can read your work free of charge

"BioMed Central will be the most significant development for disseminating the results of biomedical research in our lifetime. "

Sir Paul Nurse, Cancer Research UK

Your research papers will be:

- available free of charge to the entire biomedical community

- peer reviewed and published immediately upon acceptance

- cited in PubMed and archived on PubMed Central

- yours - you keep the copyright 